\title{
Impact of Gender Equality on Socio-Economic Development of Kazakhstan
}

\author{
Aizhan A. Mukhamadiyeva, ${ }^{+*}$ Assiya Ye. Agumbayeva, ${ }^{i}$ Kuanysh S. Alpysbayev, ${ }^{\uparrow}$ Kapura B.
} Ramazanova, ${ }^{\dagger}$ Gulnur A. Abenova,' and Raigul Zh. Duiskenova ${ }^{*}$

\section{Abstract}

Achieving gender equality in the 21st Century is one of the global priorities of every state. The Republic of Kazakhstan on its way of development also focuses on this problem, because gender equality is the basis for the economic and social development of the state. International organisations prepare reports reflecting indices (gender gap index, gender inequality index, gender development index and others) which characterise the state of equality between men and women in different countries. It was established that Kazakhstan had practically reached gender equality at the stage of education. Even the first steps towards market reforms showed the unequal impact of the socio-economic transformation on the position of men and women in society. The transition to the market was followed, on the one hand, by the curtailment of social programmes and the social sphere, and on the other hand, by an increase of labour force requirements. Under these conditions, women who traditionally bear family care, were more disadvantaged than men, both in the family and in the workplace. Democratic reforms in the post-Soviet societies created the conditions for more active participation of women in the political and economic life of the country, securing them more rights and freedoms, yet there has been a sharp deterioration in the status of women, an increase of female unemployment, the feminisation of poverty, the displacement of women in the informal economy and increase of domestic labour. Determined that the Gender Gap Index affects the gross domestic product per capita which is one of the indicators characterising the economic condition of the state. The greater the gender gap index is, the smaller is the inequality between the sexes and the higher GDP per capita is. The article presents a correlation-regression analysis which characterises the interrelation of gender equality indicators with economic indicators.

Keywords: Gender Equality, Gender Gap Index, Gender Inequality Index, Gender Equality Index, Kazakhstan

\footnotetext{
${ }^{\dagger}$ Department of Accounting and Tourism, Kazakhstan Innovative University, 071400, 5 Baiseitova Str., Semey, Republic of Kazakhstan

${ }^{*}$ Corresponding Author Email: Aizhan.Mukhamadiyeva@mail.ru

' Department of Assessment, S. Seifullin Kazakh Agrotechnical University, 010011, 62 Beibitshilik Str., Nur-Sultan, Republic of Kazakhstan

Î Sorbonne-Kazakhstan Institute, Abai Kazakh National Pedagogical University, 050000, 28 Kazybek Bi Str., Almaty, Republic of Kazakhstan

' Department of History and Ethnopolitics, Kazakhstan Innovative University, 071400, 5 Baiseitova Str., Semey, Republic of Kazakhstan

¥ Department of Economy and Tourism, University of Foreign Languages and Business Carrier, 050010, 30 Klochkov Str., Almaty, Republic of Kazakhstan

(C) 2019 Mukhamadiyeva et al. This is an Open Access article distributed under the terms of the Creative Commons Attribution License (http://creativecommons.org/licenses/by/2.0), which permits unrestricted use, distribution, and reproduction in any medium, provided the original work is properly cited.
} 


\section{Introduction}

Many local and foreign scholars, such as M. V. Shtyleva (2012), Stefan Klasen (2002), R. E. Sarbayeva (2005), etc., deal with the issues of gender equality and its impact on the economic condition of countries. During the literature review on gender equality, we found the following definitions given by various international organisations:

- Equal rights, duties and opportunities of men and women. Take into account the interests, needs and priorities of both men and women. Recognise the differences between different groups of men and women (European Institute for Gender Equality, Gender Mainstreaming, Concepts and definitions, Gender Equality, 2019).

- Equal empowerment and equal participation of both sexes in all aspects of public and private life. Accept and value the differences between men and women and their different roles in society. The right to be different. Equal access to the distribution of resources between men and women (Council of Europe, Gender Equality Commission, Gender Equality Glossary, Gender Equality, 2016).

- Gender equality is not only a fundamental human right but also the basis for a peaceful, prosperous and sustainable world. Providing women and girls equal access to education, health care, decent job and participation in political and economic decision-making processes will be beneficial to society and humankind. Implementing new legal frameworks regarding female equality in the workplace and the eradication of harmful practices targeted at women is crucial to ending the gender-based discrimination prevalent in many countries around the world (United Nations, Goal 5: Achieve Gender Equality and Empower All Women and Girls, 2016).

- Gender equality implies equal rights and opportunities for men and women in all spheres of the society, including economic activity and decision-making as well as an equal assessment and preference for different kinds of behaviour, aspirations and needs of men and women (What is Gender Equality?).

- Gender equality is equal rights, duties and opportunities for men and women, and boys and girls. Equality means that rights, duties and opportunities are independent of gender (The UN Women Training Center's Glossary, 2019).

Thus, summarising the above definitions, it can be noted that gender equality means the provision of equal rights, opportunities and access to resources regardless of gender and taking into account the differences between men and women. This is a crucial point since gender equality is not always correctly interpreted. It was revealed that part of the population believed that gender equality would be achieved if equal rights, duties and responsibilities were granted to men and women. However, in this case, missed the point that reflects the differences between men and women. For example, when we talk about equal access to work, we should remember that women are less competitive with men because they need to interrupt their professional activities during maternity leave and illnesses of children that negatively affect the opinion of employers. Therefore, in order to have equal access to work, women need certain benefits and state support.

Thus, it is possible to emphasise the importance of correct understanding of gender equality, since at present, this issue is very relevant in connection with global events which take place in the world. Reducing the role of women in the society leads to the decrease of education level since a woman is most often engaged in raising children (an educated and self-sufficient woman 
will strive to fully develop children with the help of necessary knowledge); the decrease in the health index of the population as a whole, etc. All the above factors ultimately affect the country's economy, inhibiting its growth (Ushakov, 2011; Ushakov et al. 2017a; Ushakov et al. 2017b; Van et al. 2017; Atanelishvili \& Silagadze, 2018; Silagadze, 2018; Mishchenko et al., 2018).

For studying gender equality issues, the authors should study the following issues:

- to reveal the particularities of gender inequality problems;

- to study the particularities of gender equality in different countries of the world and analyse the gender gap in Kazakhstan and other countries;

- to develop a correlation model for calculating the gender inequality index which will help trace the interconnection between the gender equality indices and economic indices;

- to make conclusions about the work done.

In the context of the above arguments, the next section reviews literature linked to gender equality.

\section{Literature Review}

Although more attention has recently been paid to gender issues in the world, in particular, in developed countries, the role of women in the economy and business is insufficient, both regarding potential and meeting the needs of the modern society. In the estimation of Booz \& Company, today, about $25 \%$ of women aged between 20 and 65 do not have the opportunity to participate in economic activities. At the same time, $95 \%$ of them live in developing countries. Therefore, the authors studied the place of gender inequality in the works of other scientists. In one of the latest interviews, Michelle Bachelet, the first female President of Chile and at present CEO of UN Women Organisation, it is emphasised that countries can benefit enormously from gender equality and therefore gender equality is what every state should strive for. The social meaning of the concept of "gender" lies in the idea of social modelling or construction of gender. Based on this, a system of behaviour norms arises in the society that prescribes the performance of certain gender roles; so, there arises a rigid series of ideas about what is "male" and "female" in this society" (Bachelet, 2016).

Traditionally, the difference in the social status of women and men and the inequality of their rights are explained by biological reasons (Grigorieva \& Chubarova, 2013). However, the analysis of historical, ethnographic and cultural facts shows that social reasons are the main factors in the opposition of the roles of women and men (Zdravomyslova \& Temkina, 2007). It is these social and cultural norms that are the object of gender studies. Gender studies touch upon the following issues: why the society treats women and men differently, why they have unequal opportunities for self-realisation in public (politics, education, other professions, cultural life) and private (housekeeping, the upbringing of children, etc.) spheres although all international documents recognise equal rights for people. However, it should be said that at the present stage of our society's development there have occurred some changes: in the construction of a democratic society, the values of a culture are changing, including the gender system. There can be observed a tendency to equalise the rights and opportunities of men and women.

The term "gender" introduced by an American psychologist Robert Stoller in 1968 (Stoller, 2016) means a set of social and cultural norms that the society requires people to follow depending on their biological sex. Gender equality is full justice in the distribution of public goods and social responsibility between women and men. To determine how to apply foreign experience in solving gender inequality in Russian practice, it is necessary to analyse the policy of gender equality in foreign countries (Zadorozhnyaya \& Naidenko, 2016). The women of the Scandinavian countries are ahead of the other countries of the world in many aspects of political participation, including the degree of 
representation in the legislative and executive bodies of government. In 1980-1990, Gro Harlem Brundtland d was three times a Prime Minister of Norway. In February 2000, in Finland, Tarja Halonen won the acute struggle with her male opponent during the presidential election and became the first female President in Scandinavia (Yaroshenko, 2015).

In 1979, the General Assembly adopted the Convention on the Elimination of all Forms of Discrimination against Women, often referred to as the International Bill of Rights for Women. In 30 articles of the Convention, it is clearly defined the concept of discrimination against women, and it is proposed an agenda for the actions at the national level which aims to put an end to discrimination. The Convention regards culture and tradition as influential forces that form gender roles and family relations as well as it is the first Human Rights Treaty that affirms women's reproductive rights (Convention on the elimination of all forms of discrimination against women, 1992).

Gender inequality is preserved in both economic and political spheres. Even though for many decades, there has been achieved inevitable progress in the labour market worldwide, women still earn, on average, $24 \%$ less than men do. As of August 2015, the presence of women in the National Parliaments is only $22 \%$. This figure had slightly increased since 1995 when $11.3 \%$ of all parliamentarians were women. (Colebatch, 2018).

Getting education by women, especially, of high level, as a rule, leads to the increase of women's employment. The analysts of Goldman Sachs (Goldman, 2018) in one of the recent reports, forecast the growth of women's employment in most countries of modern civilisations and calculated what effect this growth would have on the economy. It turned out that the reduction of the gender gap in employment can give from 0.3 to $1.5 \%$ of annual GDP growth and from 4 to $20 \%$ of per capita income growth by 2030 . It is clear that the effect will be stronger in the countries where the potential of gender gap reduction in employment is large (Egypt, Turkey), and weaker in countries where women are already actively represented on the labour market (Vietnam, China, Russia).

One more example: the elasticity of GDP per employee in relation to the resource of female education is $0.2-0.45$ (for countries with different levels of development), in relation to the resource of male education 0.3-0.1 (Goldman, 2018).

Democratic ideals of omnitude, accountability and transparency can not be achieved without laws and measures aimed to solve the gender inequality problem. Besides, these issues should be taken into account not only during the elections. On the contrary, we should make these ideas an integral part of the social, political and economic life of the society, so that girls and women could develop their potential on the equal basis with men, regardless of what they choose to be engaged. (Ki-moon, 2017)

Gender equality does not guarantee democracy.

Moreover, democracy does not guarantee gender equality. However, democracy and gender equality are maximised when the principles of people's control and equality are implemented among citizens - and the society is moving much faster along the path of development, security and protection of human rights. Vidar Helgesen, Secretary-General (Abdullah, 2010)

It has been established that in Turkey, Germany and Argentina, an employer is to bear the burden of proving that the reasons for dismissing a woman have nothing to do with her motherhood. In Korea and Turkey, it is obligatory to provide free time for prenatal medical examinations with a salary being saved. In Germany and France, institutional mechanisms have been introduced to facilitate the transition to part-time employment for family reasons. France had also implemented a programme aimed at strengthening gender equality and reducing stereotypes in the education sphere. In Brazil, China, Germany, Italy and other countries, they provide parental leave to fathers as well as develop initiatives for paternity protection (Stoller, 2016). Seemingly, in the case of India, a pregnant woman is entitled to 26 weeks of paid 
leave, which can be extended up to eight weeks as per the newly amended Maternity Act passed on 01 April 2017. Although, this Act fails to provide provisions of childcare costs; it provides work from home option for those new mothers after the expiry of 26-weeks of maternity leave. This Act makes mandatory for those organisations who employ 50 or more employees to have crèche (day nursery) (Singh, 2016). There is no provision of paternity leave for male employees, but civil servants are entitled to paternity leave of up to 15 days, which can be availed anytime from the date of delivery to six months. Indeed, by eliminating gender inequality in all spheres of public life, it is possible to reduce social tension by ensuring the stability of the public financial system, using women's potential. After all, at present, women have physical obstacles to the realisation of their abilities not only in education but also in professional activity. The question of how to achieve gender equality has a complex character. A number of the OECD working agencies have already been involved in finding ways to solve it: Committee on Public Administration, Committee on Development Assistance, Committee on Education Policy, Committee on Industry, Innovation and Entrepreneurship, Committee on Labour, Employment and Social Affairs and the others. The following section discusses the problems of gender equality.

\section{Features of Gender Equality Problems}

According to Kazakh scientists, "the achievement of gender equality and the creation of conditions for the development of women is an important factor in human development. Inefficient use of the potential of the female half of the country's population who has no equal opportunities with men in the implementation of their life plans and tasks leads to the preservation of tension at the level of interpersonal communication, institutional relations and generally between citizens and the state. The inequality of women and men is also unprofitable for the state and society economically because it hinders the development of human capital, makes projects of economic development, poverty eradication and unemployment reduction ineffective in the Republic of Kazakhstan" (Maydyrova \& Berdibekova, 2014: 23).

Stefan Clasen suggested two points in which gender equality contributes to improving the economy. Firstly, the family which is explained by the substantial female contribution of resources to the human capital of children. The result here is "an increase in productivity of the next generation of workers." The second point is the market. This is based on the assumption that innate abilities are randomly distributed between men and women and the market evens out the gender distribution of resources and opportunities and maximizes the productivity and efficiency of the human resources available in the economy" (Zadorozhnyaya \& Naidenko, 2016: 789).

An important problematic aspect of the issue of gender equality in post-Soviet countries is the unemployment of educated women. The fact is that among all workers, the level of education of women is higher compared to that of the education of men. Among students of higher educational establishments, the most substantial part of students belongs to the female sex. Having received education at Universities, women are faced with the problem of employment. Employers give preference to men (Abramova et al., 2018). Among those who occupy high positions are also men (International Labour Organisation, Gender Equality in the CIS: Overview).

This problem exists in the Republic of Kazakhstan. The positive aspect is that the country has almost achieved gender equality at the stage of education. Girls receive an even higher level of education. However, in consequence, they fall out of the labour market since marriage, and the birth of children do not allow them to realise their professional potential. This observation bear resonance to the observation made by Bhattacharyya (2016) in balancing motherhood and career in STEM jobs.

The international organisations prepare the reports which reflect indices (gender gap index, 
gender inequality index, gender development index, etc.) which characterise the state of equality between men and women in different countries. Consider one of the leading indicators of gender status, namely, the Gender Gap Index.

According to the Economic Forum, "The gender gap index is meant to measure gender differences in access to resources and

Table 1: Criteria for Measuring Gender Gaps
Parameter

Economic activity and economic
opportunities
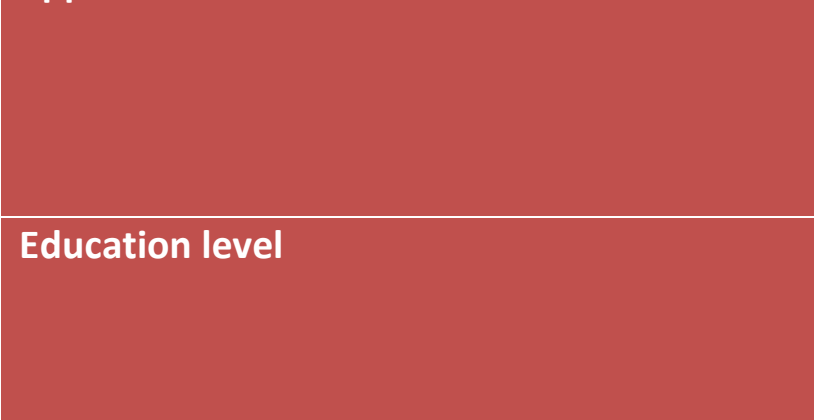

Health and Survival

Political empowerment opportunities in individual countries. Thus, the Index measures only gender differences in countries around the world regardless of their level of development." (Index of the Gender Gap According to the World Economic Forum, 2018). To measure the index, 14 different criteria are considered in four areas (Table 1) (World Economic Forum, 2017).

Labour force participation
Payment for equal work
Income
Legislative bodies, senior officials
People of intellectual labour, technical
specialists
Literacy Rate
Primary school education
Secondary school education
Higher education
Fertility
Healthy life expectancy
Parliamentary seats
Seats in ministries
Head of State (age)

\section{Characteristic}

Labour force participation

Payment for equal work

Income

Legislative bodies, senior officials

People of intellectual labour, technical specialists

Literacy Rate

Primary school education

Secondary school education

Higher education

Fertility

Healthy life expectancy

Seats in ministries

Head of State (age)

\section{Comparative Analysis of the Gender Gap in Kazakhstan and Other Countries}

The gender gap index is considered by using the example of three CIS countries (Kazakhstan, Russian Federation, Kyrgyz Republic) and two countries (Sweden, Iceland) with high index values (Table 2 ).

Based on the data of Table 2, it can be noted that the gender gap index affects the gross domestic product per capita, which is one of the indicators characterising the economic condition of the state. The greater the Gender Gap Index is, the smaller is the inequality between the sexes and the higher the GDP per capita. The European countries such as Iceland and Sweden go ahead in this indicator. The indicators of Kazakhstan and Russia are neither high nor low; the GDP is 23 or 24 thousand dollars. The Kyrgyz Republic has the lowest rates among these five countries, which show the interconnection between gender inequality and weak economies.

It is noted that for the three countries of the CIS (Russia, Kazakhstan and the Kyrgyz Republic), the issue of the salary gap between representatives of different sexes remains relevant. The practice of developed countries shows the relevant tools for ensuring equality between men and women are effective. Along with the achievement of a high level of equality, the economy is also developing in the country, and social welfare is being achieved. Table 1 with the data of the World Economic Forum reinforces this:

- Besides, according to the World Labour Organisation, closing the gender gap by $25 \%$ by 2025 will have increased global GDP by 5.3 trillion US dollars. It also shows the importance of achieving gender equality for economic growth 
(Economic Impact of Reducing Gender Gap, International Labour Organisation, 2017);

- Take into account the impact of gender equality in the economic situation of the Republic of Kazakhstan. To achieve this, we made a correlation model. To identify the interconnection between the indices as demonstrated in Tables 3 and 4.

- GDP (PPP) per capita - GDP (gross domestic product) per capita at purchasing power parity (PPP) is a characteristic that determines the level of economic development as well as economic growth. All indicators for comparability are expressed in a single currency - the US dollar (List of countries by GDP (PPP) per capita, 2018) (Table 3);

- The Gender Gap Index which characteristics was given above;

- The average age of marriage is the average age of married women.

The Global Competitiveness Index is a global study and its accompanying country ranking in terms of economic competitiveness. The Global Competitiveness Index consists of 113 variables that describe in detail the competitiveness of countries of the world at different levels of economic development.

Table 2: Gender Gap Index for 2017

\begin{tabular}{|c|c|c|c|c|c|}
\hline Indicator & Kazakhstan & $\begin{array}{c}\text { Russian } \\
\text { Federation }\end{array}$ & $\begin{array}{c}\text { Kyrgyz } \\
\text { Republic }\end{array}$ & Sweden & Iceland \\
\hline Population & 17987740 & 143964510 & 5955730 & 9837530 & 332470 \\
\hline $\begin{array}{l}\text { Population } \\
\text { growth (\%) }\end{array}$ & 1.27 & 0.04 & 1.51 & 0.75 & 0.72 \\
\hline $\begin{array}{l}\text { Ratio of the } \\
\text { number of men } \\
\text { and women }\end{array}$ & 0.94 & 0.87 & 0.98 & 1.00 & 1.01 \\
\hline $\begin{array}{l}\text { Gender Gap } \\
\text { Index }\end{array}$ & 0.713 & 0.696 & 0.691 & 0.816 & 0.878 \\
\hline $\begin{array}{l}\text { GDP (billion } \\
\text { dollars) }\end{array}$ & 133.66 & 1283.16 & 6.55 & 511.00 & 20.05 \\
\hline $\begin{array}{l}\text { GDP per capita } \\
\text { (dollar) }\end{array}$ & 23419.91 & 24026.00 & 3291.97 & 46441.21 & 45276.45 \\
\hline $\begin{array}{l}\text { Equal payroll } \\
\text { for the same job } \\
\text { (survey) }\end{array}$ & 0.725 & 0.648 & 0.706 & 0.738 & 0.807 \\
\hline
\end{tabular}

\section{Correlation Model for Calculating the Index of Gender Inequality}

Based on the source data, there should be developed a correlation model using the Microsoft Excel Software Package. We start with identifying the interconnection between such benchmarks as GDP and the Gender Gap Index. As can be seen from Figure 1, there is an interconnection between economic and gender development. There is an impact on the gender gap index on GDP per capita. Econometric modelling shows that each increase of this index leads to an increase in per capita GDP, that is, the more equal a society is, the richer it is, therefore, people are more interested themselves in developing gender balance. However, according to the Republic of Kazakhstan, it is difficult to trace this dependence due to minor fluctuations in the gender gap index and the GDP fluctuation corridor. Therefore, the coefficient of determination is low. 


\begin{tabular}{|c|c|c|c|c|}
\hline \multicolumn{2}{|c|}{ Table 3: Basic Data for the Compilation of the Correlation Model } \\
\hline & $\begin{array}{c}\text { GDP per } \\
\text { capita (PPP), } \\
\text { USD }\end{array}$ & Index & $\begin{array}{c}\text { Gender Gap Index } \\
\text { Place of the Republic of Kazakhstan in the } \\
\text { world ranking }\end{array}$ & $\begin{array}{c}\text { Average } \\
\text { age of } \\
\text { marriage }\end{array}$ \\
\hline 2008 & 19745.098 & 0.6976 & 45 & 24.4 \\
\hline 2009 & 19850.6494 & 0.7013 & 47 & 24.2 \\
\hline 2010 & 21161.2903 & 0.7055 & 41 & 24.2 \\
\hline 2011 & 24664.5161 & 0.7010 & 49 & 24.3 \\
\hline 2012 & 22640 & 0.7213 & 31 & 24.2 \\
\hline 2013 & 22107.3446 & 0.7218 & 32 & 24 \\
\hline 2014 & 22782.1229 & 0.7210 & 43 & 24.5 \\
\hline 2015 & 22675.8242 & 0.7190 & 47 & 24.7 \\
\hline 2016 & 25737.4302 & 0.7180 & 51 & 25 \\
\hline 2017 & 26088.3978 & 0.7130 & 52 & 26.3 \\
\hline
\end{tabular}

Note: Compiled from data of the World Gender Reports 2008-2017 and Global Competitiveness Reports 2008-2017

Table 4: Basic Data for the Compilation of the Correlation Model

\begin{tabular}{|c|c|c|}
\hline Year & Gender Gap Index & Global Competitiveness Index \\
\hline 2008 & 0.6976 & 4.11 \\
\hline 2009 & 0.7013 & 4.08 \\
\hline 2010 & 0.7055 & 4.12 \\
\hline 2011 & 0.701 & 4.18 \\
\hline 2012 & 0.7213 & 4.38 \\
\hline 2013 & 0.7218 & 4.41 \\
\hline 2014 & 0.721 & 4.42 \\
\hline 2015 & 0.719 & 4.5 \\
\hline 2016 & 0.718 & 4.4 \\
\hline 2017 & 0.713 & 4.3 \\
\hline
\end{tabular}

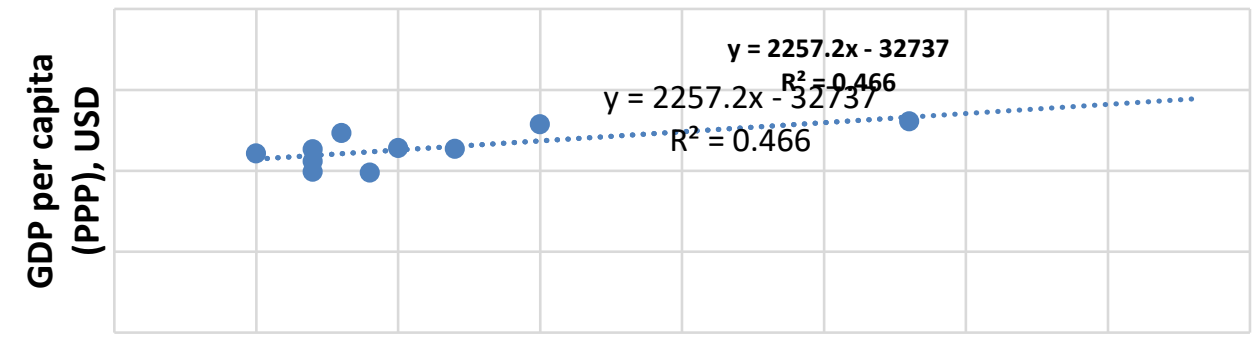

Average Age of Marriage

Figure 1: Correlation between GDP and the Gender Gap Index in the Republic of Kazakhstan 


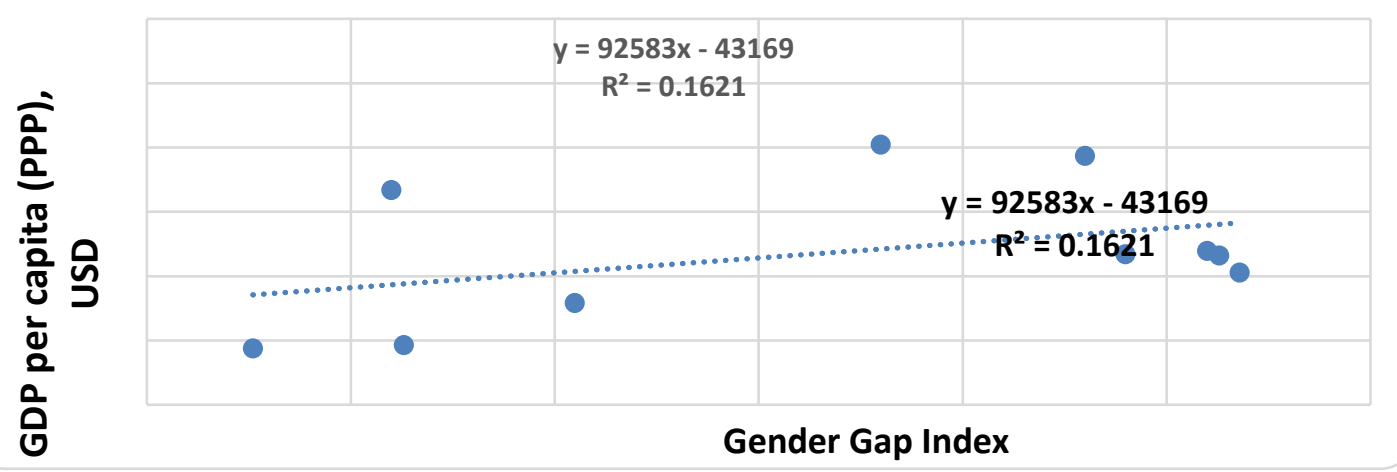

Figure 2: Correlation between GDP and the Average Age of Marriage in the Republic of Kazakhstan

Figure 2 considers the interconnection of GDP with the gender equality index. Figure 3 shows with the average age of marriage. The economic the interconnection between the gender gap competitiveness index also has interconnection index and the global competitiveness index.

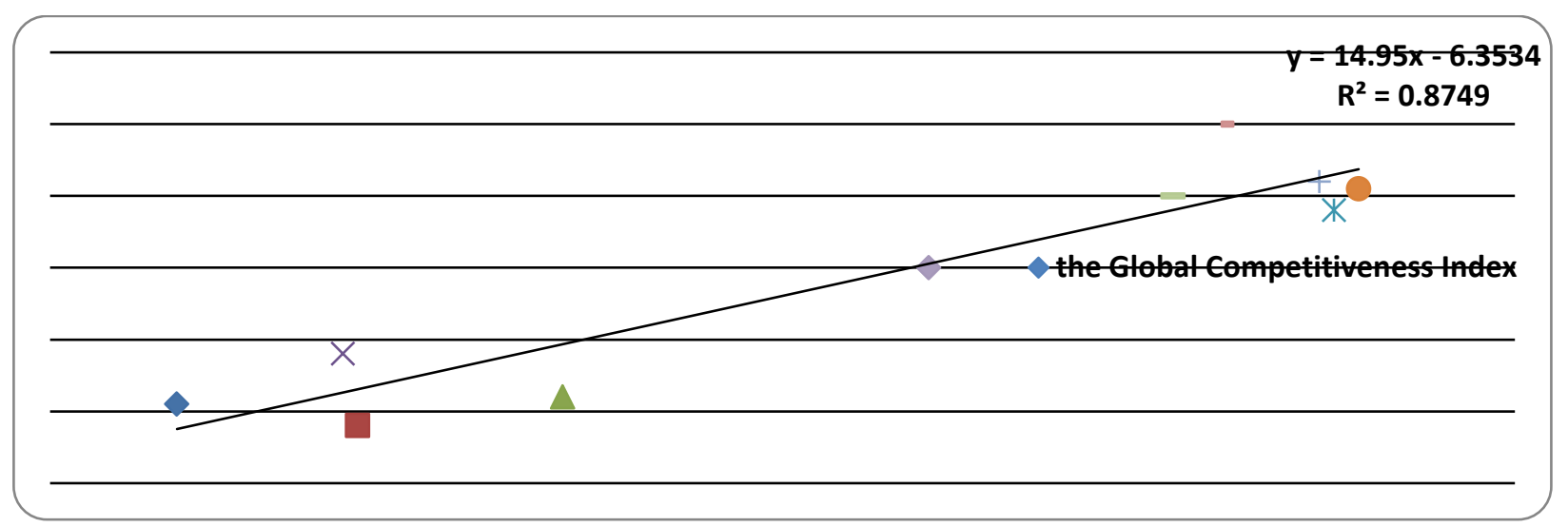

Figure 3: Correlation of the Gender Gap Index and the Global Competitiveness Index

As can be seen from Figure 3, there is a direct interconnection between the indices under consideration. For example, an increase of the gender gap index by 0.1 point leads to the increase of the global competitiveness index by 1.4 points. Consequently, gender diversity and openness of society stimulate competitiveness.

Therefore, there were created correlationregression models that allow tracing the interconnection between gender equality indices and economic indices. This leads to the conclusion about the impact of gender equality indices on economic indices which, in their turn, reveal the need to improve gender status to improve the state's economic condition.

\section{Conclusion}

In general, it can be noted that the Republic of Kazakhstan is currently paying great attention to the issue of gender equality. This is because, according to Kazakh scientists, "achieving gender equality and creating conditions for the development of women is an important factor in human development. Ineffective use of the potential of the female half of the country's population which has no equal opportunities with men in the implementation of their life plans and tasks leads to keeping tension at the level of interpersonal communication, institutional relations and in general between citizens and the state. Inequality between women and men is also disadvantageous for the state and society in economic terms since it impedes the development of human capital and makes projects for economic development, poverty eradication, and unemployment reduction ineffective. One of the main objectives of the gender policy pursued in the country is to 
refute the idea that biological differences are dominant in the behavior of men and women" (Boatsman, 2009: 12-18).

On the basis of the analysis made it is possible to note the existing interconnection between gender equality indices and economic indices that, in its turn indicates the need for taking a set of measures to improve the indices of gender equality in the Republic of Kazakhstan that will have a positive impact on the economic condition of the state.

\section{References}

Abdullah, H. (2010). Forging Ahead without an Affirmative Action Policy: Female Politicians in Sierra Leone's Post-War Electoral Process. IDS Bulletin, 41(5), 62-71.

Abramova, I. E., Ageeva, N. A., Shapoval, G. N., Lysenko, K. N., Samofalova, M. V. (2018). Russia-India: Indian students' adaptation in Russian universities in the context of the dialogue of civilizations and cultures.

Periodico Tche Quimica, 15(30), 87-94.

Atanelishvili, T., \& Silagadze, A. (2018). Formation of economic views in the ancient era. Bulletin of the Georgian National Academy of Sciences, 2(1), 191-196.

Bachelet, M. (2016, 27 January 27). Michelle Bachelet, President of Chile, "I put a person in the center of everything". Retrieved on 25 March 2019 from, https://hbrrussia.ru/liderstvo/delo-zhizni/a17093

Bhattacharyya, R. (2016). Balancing Motherhood and Career in STEM Jobs. Journal Space and Culture, India, 3(3), 28-31. https://doi.org/10.20896/saci.v3i3.178

Boatsman, I. (2009). Women and men: unequal rules in the "gender field". Moscow, Russian Federation: Tsentr Gendernykh Issledovaniy.

Colebatch, H. K. (2018). The idea of policy design: Intention, process, outcome, meaning and validity. Public Policy and Administration, 33(4), 365-383.
Convention on the elimination of all forms of discrimination against women. (1992, April). Retrieved on 19 April 2019 from, http://www.un.org/womenwatch/daw/ceda w/text/0360795R.pdf

Council of Europe, Gender Equality Commission, Gender Equality Glossary, Gender Equality. (2016, March). Equality Between Women and Men. Retrieved on 21 April 2019 from, https://rm.coe.int/CoERMPublicCommonSea rchServices/DisplayDCTMContent?document $\mathrm{Id}=09000016805 \mathrm{e} 55 \mathrm{eb}$

Economic Impact of Reducing Gender Gap, International Labour Organisation. (2017). Retrieved on 24 April 2019 from, https://www.ilo.org/wcmsp5/groups/public/ ---dgreports/--inst/documents/publication/wcms_577685.p df

European Institute for Gender Equality, Gender Mainstreaming, Concepts and definitions, Gender Equality. (2019). Retrieved on 18 March 2019 from, http://eige.europa.eu/gendermainstreaming/concepts-and-definitions

Goldman, S. (2018). When Women Lead. Retrieved on 18 March 2019 from, https://www.goldmansachs.com/

Grigorieva, N. S., \& Chubarova, T. V. (2013). Modern health care: politics, economics, management. Moscow, Russian Federation: Avtorskaya akademiya.

Index of the Gender Gap According to the World Economic Forum. (2018, 23 April). Humanitarian Encyclopedia. Retrieved on 29 March 2019 from, https://gtmarket.ru/ratings/global-gendergap-index/info

International Labour Organisation, Gender Equality in the CIS: Overview. Retrieved on 15 April 2019 from, https://www.ilo.org/moscow/areas-of- 
work/gender-equality/WCMS_249144/lang-ru/index.htm

Ki-moon, B. (2017). Report of the SecretaryGeneral on the Organisation's Work.

Retrieved on 23 April 2019 from, https://www.un.org/sg/ru/annual_report/72 .shtml

Klasen, S. (2002). Low schooling for girls, slower growth for all? Cross-country evidence on the effect of gender inequality in education on economic development. The World Bank Economic Review, 16 (3), 345-373

List of countries by GDP (PPP) per capita. (2018). Retrieved on 30 April 2019 from, https://ru.wikipedia.org/wiki/Список_стран _по_ВВП_(ППС)_на_душу_населения.

Maydyrova, A. B., \& Berdibekova, A. Sh. (2014). Gender Equality Issues in the Nation's Human Capital. Bulletin of KarSU. Retrieved on 19 April 2019 from, https://articlekz.com/article/8516

Mishchenko, V., Naumenkova, S., Mishchenko, S., \& Ivanov, V. (2018). Inflation and economic growth: The search for a compromise for the Central Bank's monetary policy. Banks and Bank Systems, 13(2), 153163.

Sarbayeva, R. E. (2005). Gender policy of international organizations in solving problems of peace and security. Bulletin of the Kazakh National University named after Al-Farabi. Series of international Relations and International Law, 1(69), 108-116.

Shtyleva, M. V. (2012). Implementing gender equality policies in the Nordic countries. Woman in Russian Society, 1, 67-80.

Silagadze, A. (2018). Some aspects of economic ideas in Shota Rustaveli's "the knight in the panther skin". Bulletin of the Georgian National Academy of Sciences, 12(1), 161167.
Singh, S. (2016). The Maternity Benefit (Amendment) Bill, 2016: A Critical Analysis. Journal Space and Culture, India, 4(2), 22-28. https://doi.org/10.20896/saci.v4i2.210

Stoller, R. (2016). Perversion. An Erotic Form of Hatred. Moscow: ERGO.

The UN Women Training Center's Glossary.

Retrieved on 19 April 2019 from, https://trainingcentre.unwomen.org/mod/gl ossary/view.php?id=36\&mode=letter\&hook= g\&sortkey=

United Nations, Goal 5: Achieve Gender Equality and Empower All Women and Girls. (2016). Retrieved on 24 April 2019 from, https://www.un.org/sustainabledevelopmen t/gender-equality/

Ushakov, D., Bandurina, N., \& Shkodinsky, S. (2017a). Country's welfare as an efficiency factor in fiscal policy promoting economic growth. Montenegrin Journal of Economics, 13(2), 30-56.

Ushakov, D. S. (2011). The problems of country's innovative capacity and investment attractiveness growth synchronization. Research Journal of Business Management, 5(4), 159-169.

Ushakov, D., Akhmetova, S. G., \& Nevskaya, L. V. (2017b). Economic growth and environmental performance: Correlation issues and future priorities. International Journal of Ecological Economics and Statistics, 38(4), 164-172.

Van, H. T., Huu, A. T., \& Ushakov, D. (2017). Liberal reforms and economic growth: Current issues and interrelations. Journal of International Studies, 10(4), 109-118.

What is Gender Equality? Retrieved on 15 April 2019 from, http://genderequality.ie/en/GE/Pages/Whati sGE

World Economic Forum. (2017). The Global Gender Gap Report 2017. Retrieved on 27 
April 2019 from,

http://www3.weforum.org/docs/WEF_GGGR _2017.pdf

Yaroshenko, S. (2015). Local Contexts of the Global Problem of Poverty Feminisation. Samara, Russian Federation: Publishing House of Samara University.
Zadorozhnyaya, E. K., \& Naidenko, I. S. (2016). Gender equality and economic growth: Interconnection of indicators. Basic Research, 11(4), 787-791.

Zdravomyslova, Ye., \& Temkina, A. (2007). Russian Gender Order: A Sociological Approach. Saint-Petersberg, Russian Federation: European Institute in SaintPetersburg. 